Proceedings of the 50th Hawaii International Conference on System Sciences | 2017

\title{
The Tale of e-Government: A Review of the Stories that Have Been Told So Far and What is Yet to Come
}

\author{
Nadine Ogonek \\ University of Muenster - European Research Center for Information Systems (ERCIS) \\ nadine.ogonek@ercis.uni-muenster.de
}

\begin{abstract}
Since its first appearance, the concept of $e$ Government has evolved into a recognized means that has helped the public sector to increase its efficiency and effectiveness. A lot of research has therefore been done in this area to elaborate on the different aspects encompassing this concept. However, when looking at the existing e-Government literature, research mostly focuses on one specific aspect of e-Government and there are few generic publications that provide an overview of the diversity of this interdisciplinary research field over a longer term period. This study analyzes the abstracts of eight e-Government journals from 2000 to 2016 by means of a quantitative text mining analysis, backed by a qualitative Delphi approach. The article concludes with a discussion on the findings and implications as well as directions for future research.
\end{abstract}

\section{Introduction and Problem Statement}

It was in the 1990s, thus more than two decades ago, when governments started their endeavor to the online world and when the term electronic government (eGovernment) was coined [4]. One quite broad definition states that e-Government is " [...] the use of information and communication technologies in public administrations combined with organizational changes and new skills. The objective is to improve public services and democratic processes" [14]. One may dare to say that it has not only considerably changed the way public administrations are operating today [19], but it has also become a broadly recognized concept that "[...] holds tremendous potential to improve the way that governments deliver public services and enhance broad stakeholder involvement in public service" [45:iii]. However, there is also a downside to it: political, organizational, social and technological challenges like e.g. continuing low adoption rates [1,24,29] or implementation issues [22,34] prevent it from tapping its full potential. The multitude of aspects eGovernment is confronted with - positively as well as negatively - justifies the growing body of literature that is exclusively dedicated to this domain: The EGovernment Reference Library (EGRL, http://faculty.washington.edu/jscholl/egrl/), hosted by the University of Washington, currently contains 7.899 peer- reviewed scientific contributions in the field of eGovernment. In 2015 alone, 664 entries were added to this overview of existing literature. The growing importance of e-Government is also acknowledged by policy makers like e.g. the European Commission who actively promotes the development of e-Government services. According to the action plan 2011-2015 by [16], it was the main goal "[...] that by 2015 50\% of citizens and $80 \%$ of businesses would use eGovernment services” [16:4].

A common vision that laid the foundation of a joint European e-Government, recorded in [15:1], envisioned for its future that by 2015 European public administrations will be "[...] recognised for being open, flexible and collaborative in their relations with citizens and businesses. They use eGovernment to increase their efficiency and effectiveness and to constantly improve public services in a way that caters for user's different needs and maximises public value thus supporting the transition of Europe to a leading knowledge-based economy."

In that respect, research presents a key driver for innovation and progress. However, to understand what topics are yet to come, it is time to pause, look back on what has been done so far, evaluate on the current status and draw conclusions from that on possible future directions for e-Government research. Even though research in e-Government is rich, of diverse nature and discipline-spanning, many studies are concerned with one specific aspect of e-Government like in $[29,34,39,50]$, just to name a few.

Quite limited attention has been devoted to gain a general overview of the research topics in the e-Government field. Undisputedly, there have been and are literature reviews that also scan the current eGovernment literature like in [21,33,38,40,42], where the authors take a broader approach. Against this backdrop, the questions to be answered in this study are 
as follows:

(1) What were the main research topics in the field of e-Government throughout the last 16 years and how did they develop over time?

(2) What research avenues can be accordingly addressed in the future?

In order to grasp the plethora of existing research as well as to uncover possible research gaps, a quantitative text mining approach with topic modelling was identified as suitable research method, since text mining techniques "[...] allow to automatically extract implicit, previously unknown, and potentially useful knowledge from large amounts of unstructured textual data in a scalable and repeatable way.” [12:556]

The performed semantic analysis to get an overview of the existing literature was supported by a qualitative Delphi approach for the interpretation of the results and the succeeding discussion on future research directions. A Delphi approach is useful "[...] for structuring a group communication process so that the process is effective in allowing a group of individuals, as a whole, to deal with a complex problem." [30:3]

The combination of automated text mining with the support of humans for the analysis of the topics and their further interpretation is novel to this approach of analyzing the extant research in the e-Government field as well as the extensive time period that, to the best of the author's knowledge, has not yet been considered in a literature review before. Hence, the aim of this study is twofold: It should provide an overview of the current body of knowledge in e-Government, facilitating the understanding of the actual state of research in this field and point to possible future research directions.

The remainder of this paper is structured as follows: In the next section, the research methodology and different steps of analysis are described in detail. Then, the results are presented in section 3 , followed by their discussion in section 4 . In the concluding section 5 that also highlights constraints and limitations a short summary of the work done is provided, together with possible areas for future research.

\section{Data Collection and Analysis Methods}

\subsection{Collection and Pre-Processing of Journal Articles}

In order to guarantee a solid literature basis, it was decided to use selected e-Government journals proposed by the EGOV Community (www.egovconference.org/journals-1) which also organizes the annual international IFIP Electronic Government (EGOV) conference, being described as "[...] the European core conference in the domain of ICT
[Information and Communication Technology] in the public sector" [42:232]. First of all, the suggestions of [48] were followed, who did an extensive literature review in the Information Systems (IS) discipline. The authors advise to start identifying relevant literature by having a look at the relevant journals, since "[t]he major contributions are likely to be in the leading journals" [48:xvi].

This selection by no means claims to be complete in terms of considered publications, since e-Government is not limited to the IS field, but is a rather interdisciplinary topic that is also of interest to such disciplines as public administration or politics. However, to get a first overview, those journals were chosen to make sure that all of the articles had a focus on the 'electronic' part of e-Government, which was crucial for the analysis.

In total, 2.269 titles and abstracts of scientific e-Government contributions were considered. All journals together with the publication year of their first issue and the respective number of considered abstracts are summarized in table 1 .

Table 1. Considered dataset

\begin{tabular}{|c|c|c|}
\hline Journal Name & $\mathbf{1}^{\text {st }}$ Issue & \# Abstracts \\
\hline $\begin{array}{c}\text { Electronic Government, an } \\
\text { International Journal (EG) }\end{array}$ & 2004 & 266 \\
\hline $\begin{array}{c}\text { Government Information } \\
\text { Quarterly (GIQ) }\end{array}$ & $2000\left(1984^{*}\right)$ & 680 \\
\hline Information Polity & $2002($ Vol.7)** & 261 \\
\hline $\begin{array}{c}\text { International Journal of } \\
\text { Electronic Governance } \\
\text { (IJEG) }\end{array}$ & 2007 & 140 \\
\hline $\begin{array}{c}\text { International Journal of } \\
\text { Electronic Government } \\
\text { Research (IJEGR) }\end{array}$ & 2005 & 207 \\
\hline Journal of E-Government & $2004-2007 * * *$ & 51 \\
\hline $\begin{array}{c}\text { Journal of Information } \\
\text { Technology and Politics }\end{array}$ & 2007 & 215 \\
\hline $\begin{array}{c}\text { The Electronic Journal of e- } \\
\text { Government (EJEG) }\end{array}$ & 2003 & 221 \\
\hline $\begin{array}{l}\text { Transforming Government } \\
\text { People, Process and Policy } \\
\text { (TGPPP) }\end{array}$ & 2007 & 228 \\
\hline $\begin{array}{l}* \\
\text { first issue |** first considered volume }\left.\right|^{* * *} \text { continued as } \\
\text { Journal of Information Technology and Politics }\end{array}$ \\
\hline
\end{tabular}

The data was gathered in a time frame from January to April 2016 and encompasses the time period from 2000 until 2016. This period was selected because [31] found that research on the use of ICT by public entities only slowly started to be of academic interest before the millennium change. This evidence is supported by the fact that the EGRL contains only 84 references before the year 2000.

If not all journals were available from this point of time, they were added from the publication of their first 
issue. Two journals changed their name within this time frame: The former Journal of E-Government was renamed into the Journal of Information Technology and Politics and the journal Information Polity was named Information Infrastructure and Policy prior to 2002. Since the Journal of E-Government had a clear eGovernment focus, it was equally incorporated whereas the journal Information Infrastructure and Policy was excluded since only two issues of volume 6 were published within the considered time horizon.

In order to ensure the text processing to be executed successfully, the data had to be in a certain format, which is why a relational database was especially designed for this purpose to aggregate the needed information (journal name, year of publication, title and abstract).

\subsection{Text Mining Approach}

It was decided to use the cloud-based, free-to-use tool MineMyText (www.minemytext.com) for the text processing. MineMyText uses a Latent Dirichlet Allocation (LDA) algorithm, a statistical model that "[...] reflects the intuition that documents exhibit multiple topics" [8:78]. This model filters the identified topics and groups them, with a topic being “[...] a distribution over a fixed vocabulary" [8:78]. The software facilitates the analysis process by offering a convenient way of applying the LDA algorithm as well as a set of integrated tools. Next to topic modelling, it features natural language pre-processing to clean texts from frequent and unnecessary words and to increase the quality of interpretations by stop word removal, ngram analysis and lemmatizing, which all have been applied in this analysis. Furthermore, it comprises visualizations for the different kinds of analysis like topic timelines that show the distribution of a respective topic over time. Those tools as well as how they were applied will be shortly explained in the following.

Using a LDA algorithm optimally fitted the objective of this research, i.e. identifying the topics e-Government scholars have dealt with in the past. The main idea of topic modelling stems from the insight that "words that occur in similar contexts tend to have similar meanings.” [44] To give a very general example: co-occurring words like “online”, “citizen”, “service”, "public", "government" could be interpreted as the topic "e-Government". The result of the analysis is a set of such co-occurring words, which then have to be further interpreted to form topics, either by humans or by further statistical approaches.

Text mining techniques originated as a means to deal with the continuously increasing amounts of data that nowadays are to be found everywhere and cannot be processed manually anymore. This situation resulted from the ever-growing appearance and increased use of web- and cloud-based systems, mobile devices and social media as well as the online storage possibilities of information. New ways of analyzing this massive information like text mining have therefore received growing attention in the last years and have already been successfully applied in research, including the IS discipline [12,17,20,47]. In this respect, this approach represents a powerful tool, because it allows to go beyond the natural boundaries of manual data analyses (quantity-wise), and quasi de facto excludes humanly induced biases (content-wise) [46].

When carrying out the three mandatory steps to perform the analysis, i.e. (1) preparing and uploading the information, (2) deciding on a number of topics and choosing the appropriate pre-processing options and (3) interpreting the details, the suggestions and instructions by [12] were closely followed. According to [12], words that appear in a high frequency can also be set as "stop words", i.e. not considering them within the analysis. The terms "e-Government" (2.576 times) and "government" (2.062 times) were among those most frequent words, which is why they were excluded since those words would not have added further value to the analysis. Furthermore, the option "standard stop words" was chosen, eliminating frequent but uninformative words like "the", "and" etc. The option "lemmatizing" was enabled, too, to only use the dictionary form of a given word, thus avoiding the repeated appearance of a single word, e.g. singular and plural of the same word. Then, the option n-gram was used and set to two. In the course of applying the LDA algorithm, normally words are split into single units (one word at a time), while in this context, it is helpful to depict more complex expressions as "digital divide" instead of "digital” and “divide”. This option was another recommendation by [12], if the latter interpretation was to be executed by humans, which is the case here. After having set all these preconditions, it was the main task to identify the ideal number of topics.

\subsection{Interpretation}

For the choice of the appropriate number of topics, a qualitative small-scale Delphi approach was applied, since it " $[. .$.$] has proven a popular tool in information$ systems research for identifying and prioritizing issues for managerial decision-making“ [36:15]. Six senior researchers from the IS field with expertise in eGovernment research ('experts') participated in the Delphi study. Instead of questionnaires, which are typically used in a Delphi study, those experts were provided with the results of the text mining analysis. Five of them have an explicit e-Government background, the sixth researcher comes from the related 
IS discipline. Their competencies are also quite diverse, going from the political perspective, technical eGovernment characteristics, social media, and education to insights into adoption factors of e-Government. The last researcher has a broad view of all IS topics and was important to bring in a more general IS-related perspective. This group was chosen because of the intended diverse research foci and differing time of affiliation to this domain, ranging from two to more than 15 years of experience. Their heterogeneity in experience and homogeneity in discipline made them share the same basic understanding, ideally complementing each other. This group played a key role within the elaboration of the topics as they were involved throughout the whole process: they (a) analyzed the optimal number of topics, (b) interpreted suitable headings that, according to their opinion, best reflected the identified topics and (c) contributed by expressing their expectations on topic outcomes. During that time, they always operated on an individual basis, independently from each other. It should be mentioned that they received the respective information on what their task was right at the time that task was due, not revealing the whole course of action from the beginning on. This was mainly done to avoid a selection bias. Given that not all of the researchers are located at the same physical location, the first rounds were executed via e-mail. The step-by-step procedure will be outlined in detail in the following:

In a first step, the researchers were asked to decide on the appropriate number of topics. For this, the 2 to 12, 14 and 16 topic distributions were explored by every member of the group individually, roughly scanning the word clouds and assigning labels to all of them. In the text mining tool, a topic is represented in flower-like word clouds, as depicted in figure 1 . Color and size of the clouds indicate the degree of relation of the given word to the respective topic.

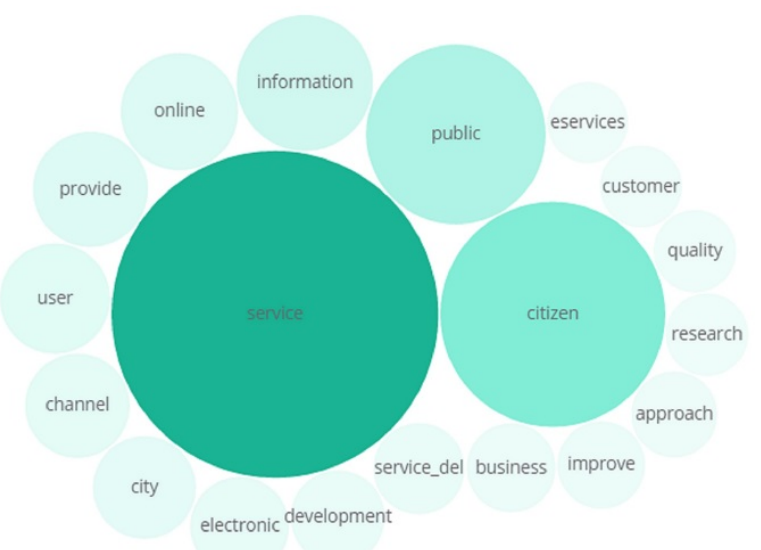

Figure 1. Most relevant words for topic $\mathbf{1 0}$
It was found unanimously that the "10 topic distribution" would fit best the purpose of this analysis. This is in line with another recommendation by [12] to choose a number of topics between ten and 50 , if the latter interpretation was to be done by humans. The " 2 topic distribution" was too generic to label it properly, whereas all topics beyond the " 10 topic distribution" did not deliver any new information but rather intermingled previously stable topic compositions. After having made the decision on the number of topics, the next step was to interpret the topics by labelling them accurately. Besides the ten most relevant words for each topic, this included the afore-mentioned graphical representation of those words (c.f. figure 1).

Table 2 contains the topic overview of the ten most relevant words and the finally assigned topic labels per topic.

\section{Table 2. Topic overview}

\begin{tabular}{|c|l|}
\hline Topic & Words \\
\hline 1 & $\begin{array}{l}\text { online, political, social_media, internet, campaign, } \\
\text { communication, party, election, medium, candidate } \\
\text { Label: e-Participation }\end{array}$ \\
\hline 2 & $\begin{array}{l}\text { factor, adoption, model, research, trust, citizen, } \\
\text { influence, system, study, level } \\
\text { Label: e-Government Adoption Factors }\end{array}$ \\
\hline 3 & $\begin{array}{l}\text { information, access, privacy, public, agency, law, } \\
\text { policy, electronic, act, security } \\
\text { Label: Governmental Information Management }\end{array}$ \\
\hline 4 & $\begin{array}{l}\text { research, study, framework, approach, development, } \\
\text { analysis, model, perspective, provide, literature } \\
\text { Label: e-Government Research }\end{array}$ \\
\hline 5 & $\begin{array}{l}\text { community, broadband, digital_divide, access, data, } \\
\text { information, service, internet, state, development } \\
\text { Label: Socio-economic Factors and Digital Divide }\end{array}$ \\
\hline 6 & $\begin{array}{l}\text { system, process, model, data, application, information, } \\
\text { approach, problem, interoperability, support } \\
\text { Label: IT and Systems Support for e-Government }\end{array}$ \\
\hline 7 & $\begin{array}{l}\text { implementation, process, organization, project, factor, } \\
\text { management, system, challenge, public_sector, } \\
\text { organizational } \\
\text { Label: Implementation and Management of e- } \\
\text { Government (Projects) }\end{array}$ \\
\hline 8 & $\begin{array}{l}\text { policy, information, public, citizen, governance, } \\
\text { technology, ict, political, transparency, participation } \\
\text { Label: Public Governance and Open Government }\end{array}$ \\
\hline 9 & $\begin{array}{l}\text { data, website, information, web_site, open_data, web, } \\
\text { quality, content, user, study } \\
\text { Label: e-Government Websites }\end{array}$ \\
\hline 10 & $\begin{array}{l}\text { service, citizen, public, information, online, provide, } \\
\text { user, channel, city, electronic } \\
\text { Label: e-Government Services }\end{array}$ \\
\hline
\end{tabular}

Already after the first round of classification, seven out of ten topics were defined and labelled relatively uniformly, only leaving nuances that needed further fine-tuning. For this reason, the group additionally received the five to seven abstracts best explaining the 
respective topics. Those abstracts were automatically assigned to the topics by the tool. Depending on the words' frequency of appearance, they received a certain percentage score: The higher the score, the better the abstract explains the topic. With the help of those best explaining abstracts, everyone was able to reassess the first decision. The idea was to provide the group with more information to better estimate the adequacy of their principal classifications, which had to be made purely on the basis of the ten most relevant words. This was done again on an individual basis. This time, however, the first round's decisions of the others were additionally disclosed. The presentation of these results as well as the insights into the best explaining abstracts helped to harmonize the chosen topics. An excerpt of the topic 10 abstracts is exhibited in table 3 .

Table 3. Best explaining abstracts of topic 10 (excerpt)

\begin{tabular}{|c|l|}
\hline \% & \multicolumn{1}{|c|}{ Abstract } \\
\hline 96.67\% & $\begin{array}{l}\text { Citizens and Service Channels: Channel Choice } \\
\text { and Channel Management Implications } \\
\text { The arrival of electronic channels in the 1990s has } \\
\text { Pad a huge impact on governmental service } \\
\text { on } \\
\text { delivery. The new channels have led to many new } \\
\text { opportunities to improve public service delivery, } \\
\text { not only in terms of citizen satisfaction, but also in } \\
\text { cost reduction for governmental agencies [...] The } \\
\text { authors will explore the channel choices of citizens } \\
\text { and further converse on how these findings may } \\
\text { help in improving channel strategies and marketing } \\
\text { and thus help in improving citizen satisfaction and } \\
\text { reduce cost of governmental service delivery. }\end{array}$ \\
\hline 95.79\% & $\begin{array}{l}\text { Issues relating to the transaction stage of the e- } \\
\text { government system } \\
\text { E-government systems pass through stages until } \\
\text { they reach the highest potential of providing } \\
\text { customers [...] with full online interaction with their } \\
\text { governments thus enabling them to obtain } \\
\text { government information and services from a single } \\
\text { point of access. The transaction stage of e- } \\
\text { government is one of the most important to the } \\
\text { implementation of an e-government system as it } \\
\text { represents the highest level of internal interaction } \\
\text { between customers and governments [...] }\end{array}$ \\
Sebie \\
et al. \\
(2005)
\end{tabular}

In a final step, to synchronize and check those results, the top 50 abstracts, available in the tool, were consulted and the topic(s), if necessary, sharpened.

\section{Results}

The final decision on the ten examined topics is presented in table 2 . This list already provides a good picture of the diversity of topics that have been addressed in the last 16 years, ranging from current issues on how to increase the number of active
e-Government users by identifying the factors that lead to adoption and use of e-Government (topic 2) to a more political perspective (topic 1 ) by analyzing the political activity in social media to foster civic participation by direct communication through various social media products (e.g. Facebook, Twitter, YouTube etc.). The analysis of the 50 best matching abstracts that put the correctness of the topic allocation to a test, allowed for a breakdown of each topic into the more precisely shaped facets that have been touched upon.

The first topic is about an element of e-democracy, namely e-participation. To understand this broad concept, [32:1] states that it is important to know that "[...] e-democracy can be divided into two distinct areas - one addressing e-participation and the other addressing e-voting.” The main difference between the two concepts, according to [23:14], lies in: "Implementing ICT in voting is mainly a question of offering a package of electronic services, such as online voting and online registration, although there are important questions of building voters' confidence in the robustness and security of the technology. Using ICT to open new channels of participation between elections, on the other hand, is much more complex." It becomes clear that this topic is predominantly concerned with the use of the internet and social media as communication means in electoral processes to foster the dialogue, engagement and active e-participation of voters, as in the study of [9]. This study analyzes, if the use of social media has implications for the degree of participation in political contexts. Looking at this topic's development over time, its importance has increased from initially $2 \%$ in the year 2000 to $17 \%$ today.

The second topic deals with e-Government adoption. The studies in this category identify factors that affect the acceptance and adoption of particular e-Government services like a tax filing system [26], oftentimes based on well-known underlying acceptance models like the Technology Acceptance Model (TAM) or the Theory of Acceptance and Use of Technology (UTAUT), which tend to be expanded by the authors according to their specific unit of analysis. In [10], for example, variables from UTAUT were combined with factors of personal perception to explain e-file adoption. Some studies also focus on one particular variable, e.g. trust like in [11]. Here, the impact of this special factor on e-Government is examined. This topic also has gained in importance throughout the considered period, starting with a share of only $1 \%$ up to more than $12 \%$ today.

Topic 3 is about the handling and management of governmental information, i.e. reporting about records or certain types of governmental information like in [6]. Studies also discuss how governments enable or restrict the access to governmental information. Amongst 
others, (lacking) access and transparency of governmental records and decision making processes as well as legal conditions, security and privacy concerns that play a role in this respect like in [25] are targeted. According to its timeline, this topic had a share of more than 30\% in the year 2000 and since then, except for a strong increase in 2002, has fallen to a share of just $4 \%$, thus being less likely to be targeted.

The next identified topic (4) deals with e-Government research. It comprises studies about the design, theoretical foundations, methodologies and research questions that have been addressed. Retrospective literature reviews like [38] provide a summary of research trends, theories and theoretical constructs. This topic started with a share of roughly $6 \%$ and has grown up to more than $20 \%$.

Topic 5 Socio-economic Factors and Digital Divide encompasses studies that examine the preconditions to implement e-Government, i.e. factors that exhibit barriers to the access and use of e-Government like the broadband provision in rural areas. According to [5:132], "[t]he digital divide refers to the distinction between the information haves and have-nots; the gap between the computer literate and the computer illiterate. More specifically, it can be argued that two major divides exist: an access divide and a skills divide." Digital divide was initially a frequently appearing topic, i.e. about every fifth contribution addressed this type of research question. Ever since its relevance has decreased considerably to just $5 \%$.

The sixth topic adopts a rather technical perspective and describes the application of ICT systems and tools, as well as methodologies and ICT architecture for the support of e-Government. Many of the abstracts in this topic focus on the use of business process management approaches like in [18] to streamline the processes of public administrations. Another element to be found here is interoperability questions and issues, i.e. discussing the degree of integration of products or systems to exchange and share their data like in [22]. A third aspect that is being addressed is the "technical" part of e-democracy, namely e-voting. Abstracts are about the use of ICT to enable, facilitate and secure evoting. Despite a strong increase in 2001, topic 6 has experienced a relatively constant development, ranging between 8 and 10\%. Since 2013 it has been exhibiting a slight downwards trend down to $6 \%$, though.

The following identified topic (7) examines e-Government from an organizational point of view by addressing the implementation and management of e-Government (projects). Studies in this category present the different sorts of challenges and how they can be overcome or why implementations projects failed in mastering those obstacles like in [2]. Implementing and managing e-Government has also undergone a quite constant development with $12 \%$ to $14 \%$ until today.

Topic 8 embraces a policy perspective. The studies at hand deal with public governance to foster openness and transparency, thus promoting the democratic process and participation by the proactive use of social media in e-Government like in [7]. This is in line with the principles of open government that, according to [49:1], creates an: “[...] unprecedented level of openness in government. We will work together to ensure the public trust and establish a system of transparency, public participation, and collaboration. Openness will strengthen our democracy and promote efficiency and effectiveness in Government." This topic had its peak in 2003 with a share of about $21 \%$ and since then has experienced a decrease to a range from $12 \%$ to $14 \%$ since 2008.

The penultimate topic (9) deals with e-Government websites. Topics under this umbrella include governmental websites as primary source of information and their contents like in [51], accessibility and usability aspects of the so-called virtual town halls. This topic, having started with a share of $12 \%$, has fallen notably to $3 \%$ between 2002/2003 and since then started to increase steadily to a share of $9 \%$ today.

The tenth topic is about the provision of e-Government services or more specifically about public service delivery including service channels, benefits and obstacles, as characterized in the abstracts shown in table 3 . This topic started with a relative share of $5 \%$ and since 2007 holds steady with a share between 8 and 10\%. An overview of the development of all ten topics is given in figure 2 .

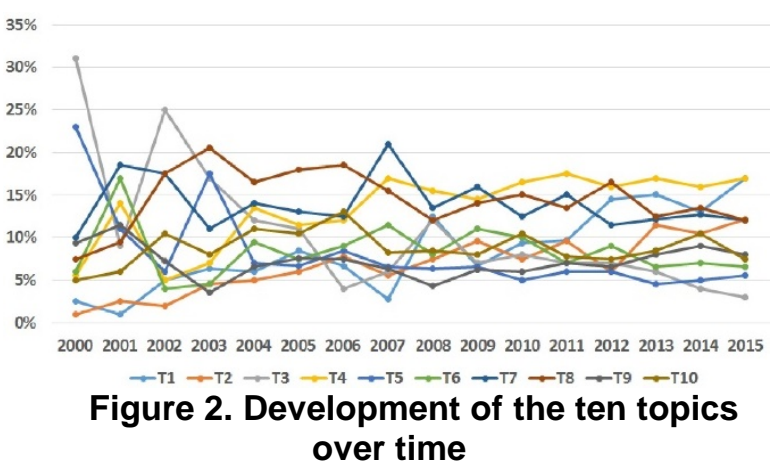

Summing up, it can be stated that the identified topics developed quite differently over time. Interestingly enough, all of them had a peak at some point of time like topic 7 in the year 2007 and then again were in line with their previous development. The majority of topics has gained in importance or at least maintained a constant development over the time horizon in question, which is in line with the general development of e-Government abstracts. The number of 
abstracts increased from initially less than 30 publications in 2000 up to more than 160 in the year 2015. Except for a peak in 2009 of more than 230 publications, it exhibits a quite constant increase throughout the considered timespan.

\section{Discussion}

When taking a look at the respective topic distributions, there are two topics that oppose the outlined development: topic 3 Governmental Information Management and topic 5 Socio-economic Factors and Digital Divide have not only experienced a slight downwards trend, but a strong continuous decline, leading to the assumption that those topics are not in the focus of e-Government scholars anymore.

Concerning topic 3 , the loss in importance might have two possible causes: privacy, access and security concerns have been probably primarily high at the very beginning of the internet era because of the new worldwide coverage and use of this medium. Furthermore, only limited or no information and experience were available and could be gathered about its potential and possible threats of the services that were suddenly available by providing personal information via online channels. Due to the meanwhile worldwide availability, more than a decade of user experience(s) and especially the change of governments from restrictive information sharing to increasing their openness and transparency under the name of Open Government, as addressed in topic 8, topic 3 has considerably lost its topicality throughout the last five years, whereas topic 8 still is in the two-digit range.

Topic 5, addressing socio-economic factors and the digital divide, has followed a similar development as topic 8. Here again, two possible reasons can be identified: when the concept of e-Government was introduced, this topic was one of the most frequently cited ones. Technologies to implement and use new services were innovative and expensive, which did not grant automatically access to everybody. Furthermore, connection problems in mainly isolated, rural areas also impeded proper access to the internet in general and consequently to the use of e-Government offers. Since that time, the technology has constantly progressed, which did not only lead to advances in area-wide broadband provisions, but also to enormous price cuts in the acquisition of computers, laptops and mobile devices, thus making ICT available to a greater share of people.

To analyze the results gained by this study in more detail and check its validity, the study by [41] is investigated that also uses a text mining approach to identify ten keyword clusters amongst the EGRL publications from 2009 to 2013 (c.f. table 4). When comparing the results of the two studies, six out of ten topics (1, 2, 3, 5, 6 and 10) can be clearly assigned to each other, e.g. keyword cluster 8 and topic 10 both target 'services'. Two more topics conform at least partly. Keyword cluster 3 is a mix of topics 1, 6 and 8 . It combines elements of e-participation, the use of IT systems and public governance. Clusters 9 and 10 are summarized in topic 2 . The last two assignable keyword clusters 6 and 8 contain superior terms, such as $e$ government and government, public administration that do not have a counterpart in this study. This is due to the fact that these words have been excluded from the analysis right from the start, given their little added value to the analysis.

What is missing completely in [41] though are the topics e-Government websites (9) and the implementation and management of e-Government (projects) (7). Also the topic e-Government research (4) seems to be only partly tapped by keyword cluster 10 , where it is about (user) acceptance as well as the technology acceptance model.

Table 4. Identified keyword clusters*

\begin{tabular}{|c|l|}
\hline$\#$ & \multicolumn{1}{|c|}{ Words } \\
\hline 1 & e-government, internet in public administration \\
\hline 2 & information \& communication technologies \\
\hline 3 & e-democracy, democracy, e-voting, internet voting \\
\hline 4 & e-participation, political participation, civic engagement \\
\hline 5 & electronic-government/public sector information \\
\hline 6 & government, public administration \\
\hline 7 & access to information, accessibility, digital divide \\
\hline 8 & information services, web services, service delivery \\
\hline 9 & adoption, technology adoption, diffusion \\
\hline 10 & (user) acceptance, technology acceptance model \\
\hline & clusters shortened and summarized by the author \\
\hline
\end{tabular}

All these findings lead to a set of possible conclusions: First, besides helping to gain an overview of e-Government research that was dealt with throughout the last 16 years, this study also identified trends of the respective topic developments by considering their distribution over time. Second, the comparison supports this study's validity, leading to very similar results, despite the use of different tools, their diverging time horizons and the consideration of different outlets. This might also shed light on the fact that the identified topics could possibly prove to be stable, also when considering different types of publications, given that those were already included in [41]. Third, the identified deviations in topic outcomes are either caused by the differences in approach or they already hint at an advancement of the body of knowledge, since the compared study was conducted in 2014. 
The study at hand suggests current and future core areas of e-Government research like e-participation (topic 1), adoption factors (topic 2) and public governance and open government (topic 8 ) that scholars can dig deeper into since they hold a lot of potential within the future development of this domain, as has also been acknowledged as key areas in strategic documents like [45]. Those topics are regarded as indispensable for a globally sustainable development and will therefore shape the design of e-Government services and how governments will interact with their stakeholders. This also offers valuable insights on how political processes with regards to public participation are currently and will keep changing in the future. Moreover, this study equally helps to identify topics that, primarily due to technological advances, seem not to be of primary research interest any more, at least at the moment and might become even less important with the ongoing technology development like issues in Governmental Information Management as well as Socio-economic Factors and Digital Divide. Nevertheless, those topics should neither be neglected nor underestimated since they are prone to societal changes as by unforeseen and exceptional circumstances like war or natural disasters that might change the preconditions for its implementation.

Besides identifying the topics of greatest interest, this study also reveals areas that none or only limited attention has been paid to so far. In a semantic analysis this can happen, if a topic is a trend that has only recently emerged and therefore could not yet be picked up in e-Government journals. Then, the topic might be of special interest for a limited audience or it merely represents a more specialized subtopic of a superordinate area. The latter finding was also flagged by the experts, when gathering the final topic sets. Some experts stated that they would have expected such topics as the legal conditions of e-Government or interoperability-related topics to be more present, which only appear as integral parts of the superordinate topics 3 and 6.

Another topic that the experts would have expected as a key topic, also identified by [43], is the topic of eGovernment education. This topic is also apparently too young in terms of appearance in scientific contributions. Though being a necessary prerequisite for successful eGovernment implementation, providing for more efficiency and effectiveness, it has gained limited attention so far, except for recent ventures like $[13,27,28]$.

Despite the topics that are to be unveiled yet, there are other emergent topics that will possibly increase in importance. An example for this is the omnipresent topic of demographic change and the handling of the triangle ICT, government, and an aging population, as being addressed by [35]. Further possible upcoming topics are being addressed by e-Government conferences, featuring tracks on new and emerging topics like the HICSS 2017 minitrack: Emerging topics in Electronic Government. Here, topics as, e.g. "robotic technology in and for government", "mobility and egovernment transformation: challenges and opportunities" or "e-law and e-justice".

How to treat all these topics, those that are new, subordinate to other topics or those that might need to form proper topics in the future because of their increasing relevance, represents an area for future research endeavors.

This topic variety shows that the field of e-Government is still far from being fully explored. New and innovative ideas are being constantly brought up to improve government's online services and user focus.

\section{Limitations, Critical Reflection and Conclusion}

Limitations. This research is also subject to limitations. As mentioned in the beginning, only designated e-Government journals have been examined here. Other outlets like renowned IS journals, e.g. the journal Management Information Systems Quarterly (MIS Quarterly) or renowned journals in related disciplines, like the public administration discipline, where e-Government also has been a topic of discussion and research, were completely neglected in this article as well as important conference proceedings that equally present novel and important research in the field.

Another limitation of this study is the diverging number of abstracts of the journals at hand. The journal Government Information Quarterly (GIQ) by far outperforms the other considered journals with an abstract number of 680 whereas the others range between 140 and 260. As a corollary, this has also implications for the shape of the modelled topics, i.e. the abstracts of the GIQ naturally had a greater stake in the analysis and thus will most probably have greatly influenced the topic composition. Given that the GIQ also forms part of the designated e-Government journals, the published contributions are in line with the other journals, which is why this bias is not of greater concern here.

The last limitation is about the applied methods. Due to the fact that the underlying algorithm of the text mining tool is nondeterministic, every time the analysis is run again, it might deliver slightly different results with partly differing words. However, it was possible to re-identify practically all the topics again, which also sheds light on the topics' quality and robustness. Then the topic identification and interpretation is naturally 
prone to the subjective opinions of the respondents, which was attempted to be minimized by involving a diverse group of people.

Having said all this, these limitations equally depict possible future research opportunities for deeper investigation: First of all, different types of analysis (qualitative and quantitative) could be applied to redo this study and safeguard its validity. Then, outlets from related disciplines should be certainly considered in a next step, e.g. comparing these topics with the ones of related disciplines to see whether they cover the same or different aspects. This holds equally true for different types of publications like conference proceedings or book chapters, which should be taken into account, too. The questions to be answered will, amongst others, be: Will those address similar topics or are they different to what is being addressed here?

Critical Reflection and Conclusion. The main objective of this research was to identify a set of topics that best represent the e-Government research of the last 16 years. The ten topics derived from the analysis shall enhance the understanding of the actual state of research on e-Government. The presented topic overview is a first indication of the topics that are well represented and all those that are lacking here, either because they cannot even be thought of at this stage of time, or because they represent relatively young trends that need to and probably will gain more attention.

Those ten topics actually are the stories that turned the field of e-Government into what it has become today. On the one hand, they offer scientific implications on further research directions. On the other hand, they can also provide practical guidance for governments on how to position themselves in this context, i.e. which topics to prioritize and subsequently which strategies to pursue with regards to governmental policy, user focus and amelioration of service delivery. This study can be seen as the starting point for further reviews to reassess how the research in this discipline will have evolved and/or changed by then in terms of focal points as well as importance. Will e-Government as a discipline stay as important as it is perceived today or will it be substituted by something else? On the basis of this study, possible future research paths were identified for e-Government scholars to build on and extend its body of knowledge, thus continuing to tell the stories of the future.

\section{References}

[1] Akkaya, C., Obermeier, M., Wolf, P., and Krcmar, H. Components of Trust Influencing eGovernment Adoption in Germany. Electronic Government: Proceedings of the 10th IFIP WG 8.5 International Conference, EGOV 2011, (2011), 88-99.
[2] Al-Sebie, M. and Irani, Z. Technical and organisational challenges facing transactional e-government systems: an empirical study. Electronic Government: An International Journal 2, 3 (2005), 247-276.

[3] Al-Sebie, M., Irani, Z., and Eldabi, T. Issues relating to the transaction stage of the e-government system. Electronic Government: An International Journal 2, 4 (2005), 446-459. [4] Anthopoulos, L.G. and Reddick, C.G., eds. Information and communication technologies in public administration : innovations from developed countries. CRC Press : Taylor \& Francis Group, Boca Raton, 2015.

[5] Bélanger, F. and Carter, L. The impact of the digital divide on e-government use. Communications of the ACM 52, 4 (2009), 4-7.

[6] Bernholz, C.D. and Ellis, W.R. The Missing Court of Claims Report: Is Letitia Humphreys Court of Claims Report 42? Government Information Quarterly 23, 2 (2006), 309324.

[7] Bertot, J.C., Jaeger, P.T., and Grimes, J.M. Using ICTs to create a culture of transparency: E-government and social media as openness and anti-corruption tools for societies. Government Information Quarterly 27, 3 (2010), 264-271. [8] Blei, D. Probabilistic topic models. Communications of the ACM 55, 4 (2012), 77-84.

[9] Bode, L. Facebooking It to the Polls: A Study in Online Social Networking and Political Behavior. Journal of Information Technology \& Politics 9, 4 (2012), 352-369.

[10] Carter, L., Schaupp, L.C., Hobbs, J., and Campbell, R. The role of security and trust in the adoption of online tax filing. Transforming Government: People, Process and Policy 5, 4 (2011), 303-318.

[11] Das, J., DiRienzo, C., and Burbridge John, J. Global EGovernment and the Role of Trust: A Cross Country Analysis. International Journal of Electronic Government Research 5, 1 (2009), 1-18.

[12] Debortoli, S., Junglas, I.A., Müller, O., and vom Brocke, J. Text mining for information systems researchers: An annotated topic modeling tutorial. Communications of the AIS, forthcoming (2016), 555-582.

[13] Estevez, E. and Janowski, T. Landscaping Government Chief Information Officer Education. Proceedings of the 46th Hawaii International Conference on System Sciences (HICSS-46), IEEE (2013), 1684-1693.

[14] European Commission. eGovernment. 2006. http://bit.ly/1UyXy1U.

[15] European Commission. Ministerial Declaration on eGovernment. Malmö, 2009.

[16] European Commission. European eGovernment Action Plan 2011-2015. Brussels, 2010.

[17] Evangelopoulos, N., Zhang, X., and Prybutok, V.R. Latent Semantic Analysis: five methodological recommendations. European Journal of Information Systems 21, 1 (2012), 70-86.

[18] Freiheit, J. and Zangl, F.A. Model-based User-interface Management for Public Services. Electronic Journal of eGovernment 5, 1 (2007), 53-62.

[19] Gascó, M. New Technologies and Institutional Change in Public Administration. Social Science Computer Review 21, 1 (2003), 6-14.

[20] Gorbacheva, E., Stein, A., Schmiedel, T., and Müller, O. The Role of Gender in Business Process Management 
Competence Supply. Business and Information Systems Engineering (BISE) 58, 3 (2016), 213-231.

[21] Grönlund, Å. State of the Art in E-Gov Research: Surveying Conference Publications. International Journal of Electronic Government Research 1, (2005), 1-25.

[22] Hellberg, A.S. and Gronlund, A. Conflicts in implementing interoperability: Re-operationalizing basic values. Government Information Quarterly 30, (2013), 154162.

[23] HM Government. In the service of democracy: A consultation paper on a policy for electronic democracy. London, 2003.

[24] Hofmann, S., Räckers, M., and Becker, J. Identifying Factors of E-Government Acceptance - A Literature Review. 33rd International Conference on Information Systems (ICIS 2012), (2012), 1-10.

[25] Hogenboom, K. Lessons Learned about access to government information after World War II can be applied after September 11. Government Information Quarterly 25, 1 (2008), 90-103.

[26] Hung, S.-Y., Chang, C.-M., and Yu, T.-J. Determinants of user acceptance of the e-Government services: the case of online tax filing and payment system. Government Information Quarterly 23, 1 (2006), 97-122.

[27] Hunnius, S., Paulowitsch, B., and Schuppan, T. Does EGovernment education meet competency requirements? An analysis of the German university system from international perspective. Proceedings of the 48th Hawaii International Conference on System Sciences (HICSS-48), IEEE (2015), 2116-2123.

[28] Hunnius, S. and Schuppan, T. Competency requirements for transformational e-government. Proceedings of the 46th Hawaii International Conference on System Sciences (HICSS-46), IEEE (2013), 1664-1673.

[29] Kumar, V., Mukerji, B., Butt, I., and Persaud, A. Factors for successful e-government adoption: a conceptual framework. Electronic Journal of e-Government 5, 1 (2007), 63-76.

[30] Linstone, H.A. and Turoff, M., eds. The Delphi Method: Techniques and Applications. Addison-Wesley Publishing, Boston, 2002.

[31] Liu, S.M. and Yuan, Q. The Evolution of Information and Communication Technology in Public Administration. Public Administration and Development 35, 2 (2015), 140151.

[32] Macintosh, A. Characterizing E-Participation in PolicyMaking. Proceedings of the 37th Hawaii International Conference on System Sciences (HICSS-37), IEEE (2004), 110.

[33] Madsen, C.Ø., Berger, J.B., and Phythian, M. The Development in Leading e-Government Articles 2001-2010: Definitions, Perspectives, Scope, Research Philosophies, Methods and Recommendations: An Update of Heeks and Bailur. Electronic Government: Proceedings of the 13th IFIP WG 8.5 International Conference, EGOV 2014, (2014), 1734.

[34] Müller, S.D. and Skau, S.A. Success factors influencing implementation of e-government at different stages of maturity: a literature review. International Journal of Electronic Governance 7, (2015), 136-170.

[35] Niehaves, B. Iceberg ahead: On electronic government research and societal aging. Government Information Quarterly 28, 3 (2011), 310-319.

[36] Okoli, C. and Pawlowski, S.D. The Delphi method as research tool: an example, design considerations and applications. Information \& Management 42, 1 (2004), 1529.

[37] Pieterson, W. Citizens and Service Channels: Channel Choice and Channel Management Implications. International Journal of Electronic Government Research 6, 2 (2010), 3753.

[38] Rana, N.P., Williams, M.D., Dwivedi, Y.K., and Williams, J. Reflecting on E-Government Research.

International Journal of Electronic Government Research 7, 4 (2011), 64-88.

[39] Scherer, S. and Wimmer, M.A. Trust in e-Participation: Literature Review and Emerging Research Needs. 8th International Conference on Theory and Practice of Electronic Governance, ICEGOV 2014, ACM (2014), 61-70. [40] Scholl, H.J. The EGOV Research Community: An Update on Where We Stand. Electronic Government: Proceedings of the 13th IFIP WG 8.5 International Conference, EGOV 2014, 1-16.

[41] Scholl, H.J. The EGOV Research Community: An Update on Where We Stand. Electronic Government: Proceedings of the 13th IFIP WG 8.5 International Conference, EGOV 2014, (2014), 1-16.

[42] Scholl, H.J. and Dwivedi, Y.K. Forums for electronic government scholars: Insights from a 2012/2013 study. Government Information Quarterly 31, 2 (2014), 229-242. [43] Schuppan, T., Pardo, T.A., and Wihlborg, E. Introduction to emerging topics in electronic government minitrack. Proceedings of the 48th Hawaii International Conference on System Sciences (HICSS-48), IEEE (2015), 335.

[44] Turney, P.D. and Pantel, P. From frequency to meaning: Vector space models of semantics. Journal of Artificial Intelligence Research 37, (2010), 141-188.

[45] United Nations. E-Government for the Future We Want. New York, 2014.

[46] Urquhart, C. An Encounter with Grounded Theory: Tackling the Practical and Philosophical Issues. In E.M. Trauth, ed., Qualitative Research in IS: Issues and Trends. Idea Group Publishing, Hershey, 2001, 104-140.

[47] Vakulenko, S., Müller, O., and Brocke, J. Enriching iTunes App Store Categories via Topic Modeling.

Proceedings of the 35th International Conference on Information Systems, (2014), 1-11.

[48] Webster, J. and Watson, R.T. Analyzing the Past to Prepare for the Future: Writing a Literature Review. MIS Quarterly 26, 2 (2002), xiii-xxiii.

[49] White House. Memorandum on Transparency and Open Government. Washington, 2009.

[50] Yang, T.-M. and Maxwell, T.A. Information-sharing in public organizations: A literature review of interpersonal, intra-organizational and inter-organizational success factors. Government Information Quarterly 28, 2 (2011), 164-175. [51] Yu, D.X. and Parmanto, B. U.S. state government websites demonstrate better in terms of accessibility compared to federal government and commercial websites. Government Information Quarterly 28, 4 (2011), 484-490. 